\title{
Developing school leaders: Responses of school leaders to group reflective learning
} Ellen Daniëls ${ }^{1 / 2}$, Annie Hondeghem ${ }^{2}$, Jan Heystek ${ }^{3}$

\author{
${ }^{2}$ Public Governance Institute - Faculty of Social Sciences (KU Leuven) \\ Parkstraat 45 bus 3609, 3000 Leuven - Belgium \\ ellen.daniels@kuleuven.be \\ annie.hondeghem@kuleuven.be \\ ${ }^{3}$ Research Niche Unit Edu-Lead - Faculty of Education (North-West University) \\ 11 Hoffman Street, Building C6, Office 258, Potchefstroom - South Africa \\ jan.heystek@nwu.ac.za
}

\begin{abstract}
Throughout the past decades, the profession of school leader has become more complex. To deal with these increasing complexities and the challenges school leaders encounter, it is important that school leaders are provided with effective professional development. However, research on school leaders' learning and professional development, and especially on school leaders' group reflective learning, is still rather limited. Based on findings of a few previous studies considering school leaders' professional development, a group reflective learning programme was developed. The current qualitative study unravels school leaders' reactions with regard to group reflective learning programmes through interviewing the 19 participants of the programme.

The study of the school leaders' reactions shows that school leaders set particular preconditions for group reflective learning, that they value recognition and support of fellow school leaders, and that they appreciate the programme because they were able to learn from their own, and their fellow school leaders' daily-life experiences. Group reflective programmes have the potential to develop knowledge, skills and/or attitudes and seem to satisfy the statement that school leaders need to be provided with appropriate professional development programmes to prevent job related psychological issues.
\end{abstract}

\section{Keywords}

School leaders' learning

Professional development

Reflective learning

Collaborative learning

\section{Introduction}

Several scholars stated that school leadership is a complex and challenging job. School leaders have the challenging task of leading in times of socio-economic changes and high accountability, which makes the job even more complex and stressful. Classes become increasingly diverse, resulting in school leaders who provide more support to teachers and to teachers' professional development to ensure appropriate education. Moreover, school leaders have to deal with teacher turnover and teacher shortages. Research shows that the complexity of school leaders' work can lead to inordinate amounts of stress and eventually burnout (Battle, 2010; Devos, Vanblaere \& Bellemans, 2018; Fullan, 2009; Normore, 2007). This implies that school leaders need to be supported and provided with appropriate

\footnotetext{
${ }^{1}$ Corresponding author: ellen.daniels@ kuleuven.be
} 
continuous professional development opportunities to keep their skills up-to-date, to prevent drop out and job related psychosocial issues, and to support teachers and teachers' professional development (Devos et al., 2018; Elmore, 2000; La Pointe \& Davis, 2006). Drago-Severson (2012) point to prioritising and securing time and resources for all adults at school, including school leaders, to engage in reflective learning practices with colleagues, in order to ensure continuous learning across all levels of the school organization.

To be able to deal with these complexities and challenges, it is important that school leaders are trained properly and that they among others participate in continuing professional development to deal with these emerging challenges effectively. So far, little research has been conducted on reflective learning programmes for school leaders. However, Drago-Severson (2012) reported that school leaders stressed the importance of renewal through reflecting on thinking and practice in company of colleagues. Peer school leaders can support each other through reflection as they work their way through and support each other to manage changes more effectively. School leaders' engagement in reflective learning can positively influence the school climate and teacher growth (Donaldson, 2008; Youngs \& King, 2002). The emphasized collaborative aspect of reflective learning aligns with an important aspect of work motivation: connectedness to others (Hawkins, 2014). The importance of connectedness to others and the power of the group is a main reason for establishing collaborative continuous professional development (Aas \& Vavik, 2015; Flückiger, Aas, Nicolaidou, Johnson \& Lovett, 2017).

In a qualitative study of Authors (1) considering Flemish school leaders' professional development, school leaders indicated that they favour conversations with fellow school leaders, asking colleagues and teachers for feedback, and that they favour reflective learning. This aligns with the recommendations of the study of Devos et al. (2018). They refer among others to reflective learning in peer groups, and emphasize the importance of the specific needs of the particular school leader and context.

The current paper researches the perceptions of school leaders about a group reflective learning programme in which reflective learning in company of peers is central. Reflection is understood as an activity in which 'an individual steps back from particular experiences in order to analyse the meaning to the self' (Hulsbos, Evers \& Kessels, 2016, p.24 \& p.32; Daudelin, 1996). Aas (2016) defines reflective learning as 'the critical investigation of an individual's own practice in order to provide professional learning and development'.

The aim of the study is to gain a deeper insight in school leaders' perceptions about this type of professional development and to contribute to the empirical base for a broader approach on group reflective learning among school leaders. The study questions how school leaders respond to the group reflective learning programme. A positive response to professional development activities is a relevant step in achieving deep learning (Kirkpatrick, 1994; Phillips, Stone \& Phillips, 2001). Contributing to the insight in school leaders' responses to this particular type of professional development is of interest because it is under researched and a first step to eventually research the possible learning results and organizational change. Moreover, an increased insight in school leaders' professional development can contribute to effective programmes for school leaders' professional development. Furthermore, an insight in experiences with reflective learning is important, because it is known that positive experiences with professional development activities and more in particular, learning activities in company of peers, have the potential to facilitate the development of school leaders' and moderate their stress levels (Devos et al., 2018; Drago-Severson, 2012).

\subsection{Context of the study}

The current study was conducted in primary schools in Flanders, the northern part of Belgium. A single school leader taking the formal daily lead over the teachers and the administrative employee characterizes the organizational structure of Flemish primary schools. The average school leaderteacher ratio is 1:20 - 1:35. Apart from the teachers and the administrative employee, primary schools employ a special needs coordinator who takes the lead in developing and implementing a tailor-made policy on special needs. Primary schools have autonomy in making use of the position of the special needs coordinator (Flemish Education Council, 2003). 
Professional development for school leaders is not compulsory in Flanders. However, the majority of the Flemish primary school leaders (94\%) participate annually in professional development activities (Authors, 1). Professional development for school leaders is provided by the educational umbrella organizations ${ }^{2}$, universities, universities of applied sciences but also by other organizations. Reflective group programmes exist, but are often carried out in the absence of a trainer. A trainer is understood as someone who keeps track of the reflective learning in the programme and ensures that the group stays focused and prevents the process resulting in superficial and meaningless conversations. The groups mostly consist of acquaintances. In the study of Authors (2), 30\% indicated that in the previous school year they had participated in group reflective learning programmes. Moreover, the school leaders indicated also indicated that these particular trainings were useful (80\%) and 76\% stated that they made use of the knowledge they had gained during this training (Authors, 2).

\section{Theoretical Perspectives}

\subsection{Continuous professional development of school leaders}

In contemporary times, there is ample attention to participate in continuous professional development (CDP) to keep professional knowledge, skills and attitudes up-to-standards. The literature on CPD emphasizes the continuity beyond the pre-service training and focuses on the participation in professional development activities. Mitchell (2013) describes continuous professional development as a 'process whereby an individual acquires or enhances the skills, knowledge and/or attitudes for improved practice' (p.390). CPD can be structured and organized in a number of different ways including many different forms of professional development in face-to-face and online contexts (Peterson, 2002; Stevenson, Hedberg, O'Sullivan \& Howe, 2014). Huber (2011) distinguishes three main categories of school leaders' CPD: (1) cognitive theoretical ways of learning, (2) cooperative and communicative process-oriented procedures, and (3) reflexive methods. Cognitive theoretical learning includes among others lectures and self-study. Cooperative and communicative process-oriented procedures include i.e. group and project work. Reflexive methods contain methods such as feedback and reflective learning supervised by a trainer. The programme, which is subject to the current study, belongs to the last category of reflexive methods. Authors (1) conducted an extensive review on school principals' leadership development and found five categories to take into account in the development of school leaders' professional development: (1) prior learning and the professional development needs of the school leader; (2) the contextual and experiential aspect of school leaders' CPD, including reflective learning and action research; (3) transfer of knowledge skills and attitudes to practice to obtain an effect; (4) networking and collegial consulting in terms of sharing ideas, reactivating knowledge and easing the feeling of loneliness and (5) the spread over time and ongoing support of CPD to extend and redefine school leaders' daily experiences. Similarities with the constructivist approach to learning and the latter findings of Authors (1) are noticeable. The constructivist approaches to learning consists of four generally accepted principles: (1) learners construct their own meaning, (2) learning builds on prior knowledge, (3) learning is enhanced by social interaction and (4) meaningful learning develops through authentic learning tasks (Good \& Brophy, 1994). This aligns with the suggestions of Authors (1) to consider prior learning, the suggestion that school leaders' professional development should be contextual and experiential, and hence include reflective learning and the importance of networking and collegial consulting. Constructivist approaches to learning assume that

\footnotetext{
${ }^{2}$ Umbrella organization: In Flanders, there are four main umbrella organizations: the Catholic Umbrella Organization, Umbrella Organization of the Education of Flemish Community, the Umbrella Organization of Education of Cities and Municipalities, and the Umbrella Organization Provincial Education. These umbrella organizations (UO) are support and represent school boards, prepare curricula and class schedules. The UO develop among others initiatives to support schools, to improve the quality of education and to strengthen the professional skills of staff members. (Flemish Ministry of Education, 2019)
} 
understanding comes from a process of inquiry and reflection (Meisel, 2012). Problem-based learning is one of the methods that helps create learning environments based on the constructivist approach (Inel \& Balim, 2010).

Additionally, several scholars have suggested that continuous professional development should take place in the context of teams because of the complex nature of contemporary jobs (f.i. Paulus \& Nijstad, 2010; Van den Bossche, Gijselaers, Segers \& Kirschner, 2006). Teams consist of people with different experiences, values and knowledge sets, and hence are expected to be more effective in adequately solving problems than individuals (Van den Bossche et al., 2006). According to Aas \& Vavik (2015), groups create social learning environments with opportunities for contextual feedback from peers. This feedback broadens the participants' thinking about their performance. Sanner \& Bunderson (2015) add that groups vary in composition and number, and they emphasize the importance of psychological safety in groups in the context of professional development (Sanner \& Bunderson, 2015). Team psychological safety is a tacit belief and is not given direct attention by individual participants nor by the team as a whole, though it is a precaution to open up and allow deep reflective learning. Edmondson (1999) defines team psychological safety as 'a shared belief that the team is safe for interpersonal risk taking'. Psychological safety refers to confidence that is based on mutual respect and trust among the team members (Edmondson, 1999). In safe teams, team members can ask for help, are admitted to make mistakes, are prepared to present new ideas and can express their concerns. The latter prevents possible feelings of embarrassment or threat, which can hamper learning (Edmondson 1999, 2008).

\subsection{Evaluation of training}

Evaluating professional development programmes and evaluating learning outcomes of professional development programmes is important. Without learning, no change in behaviour will occur (Kirkpatrick \& Kirkpatrick, 2006). A commonly accepted model to evaluate training effectiveness is Kirkpatrick's Hierarchical Model of Training Outcomes (1959, 1994). The model consists of four levels: reaction, learning, behaviour and results. In the discussion of the model, more attention is paid to the first level (reaction) because the first level is the central focus of the current article. Reaction is the level that includes the extent to which participants are satisfied with the training programme and is considered as an important level. If participants perceive the training as irrelevant or inappropriate, then the training is not meaningful to the participants and has only little chance to be successful (Phillips et al., 2001). Kirkpatrick \& Kirkpatrick (2006) state that participants will not be motivated to learn if they do not react to the programme in a favourable way. Therefore, questions measuring the reaction level ideally gauge participants' overall satisfaction, the satisfaction with the quality of the provided activities and the trainer (DeSilets, 2018).

The level 'learning' refers to the extent of development of knowledge, skills and attitudes induced by the training. The level behaviour comprises the extent to which participants apply the gained knowledge, skills and attitudes (at the school) and eventually, the level of results refers to the extent to which the training contributes to the achievement of the goals of the school. The four levels represent a sequence of ways to evaluate training programmes. While moving from one level to the next level, the process becomes more difficult and time-consuming, but it provides more and valuable information (Kirkpatrick, 1994).

Figure 1

Kirkpatrick's four level model of training evaluation (model adapted from Kirkpatrick, 1994) 


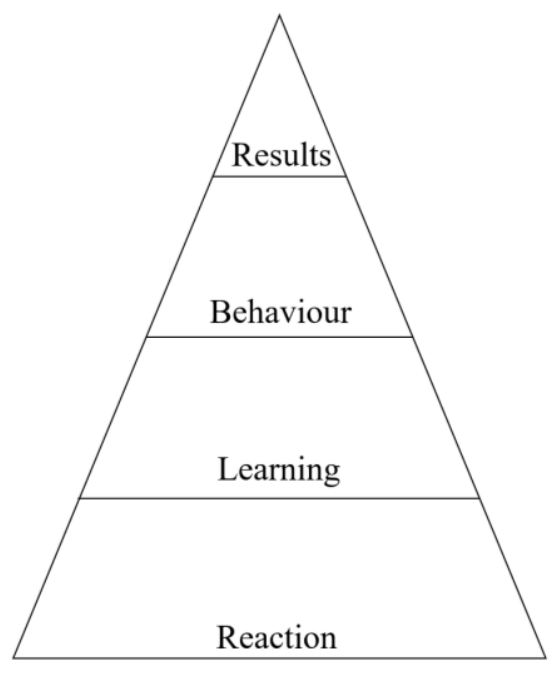

Results: How did the training influence a possible

change in organizational performance?

Behaviour: Did the participants change their behaviour as a result of the training? How?

Learning: How did the participants possibly improve their knowledge, skills and/or attitudes as a result of the training?

Reaction: How did the participants enjoy the training?

\subsection{The group reflective learning programme}

The following paragraph explains the design of the group reflective learning programme. The programme was developed based on the insights from exploratory studies (Authors 1, $2 \& 3$ ) and for the sake of the research project. The design fits within a constructivist approach on learning and was developed bearing in mind the principles of effective school leaders' development (cfr. Authors, 1; Huber, 2011).

The groups consisted of six to seven participants supervised by an experienced trainer. A group size of six to seven members is suitable to develop context-based competences and to build an atmosphere for sharing personal experiences and feelings (Aas \& Vavik, 2015). Moreover, the school leaders were sampled and assigned to a group ensuring that they did not know each other prior to the training. The latter was important with regard to establishing a safe climate in the groups. A safe climate fosters school leaders' willingness to share (personal) cases and allows reflective learning to move beyond surficial reflections (see infra). The groups were compiled using the strategy of maximum variation considering seniority, gender and umbrella organization. The geographical location was taken into account in terms of spread but the feasibility to travel to the training location as well. The role of the trainer is important for group reflective learning in order to keep the group focused and to prevent the group from engaging in superficial and informal reflective chats (Aas \& Vavik, 2015; Dyke, 2014; Korthagen \& Wubbels, 2001). The trainer was experienced on guiding group reflective learning and was hired from a University of Applied Sciences (UAS) for the sake of the programme. The relevant UAS, has a tradition on group reflective learning in among others bachelor degrees in education and advanced bachelor degrees in education. The advanced bachelor degrees are predominantly followed by working students (in case teachers and school leaders) and hence, the experience and skills of the trainer were relevant for guiding school leaders' group reflective learning.

The programme consisted of eight sessions. The outline of the sessions will be explained based on Step, Depuydt, Mertens, Delathouwer \& Author (2018). The first session was an introductory session in order to become familiar with the technique and make room to build trust to ensure psychological safety. Psychological safety is a necessity to ensure that the team members feel safe to share their personal issues. Psychological safety is understood as a shared belief that the team is safe for interpersonal risk taking (Edmondson, 1999).

From the second session onwards, one school leader reported alternately on a self-selected case, related to the topic of the programme: coaching, supporting and motivating teachers. Prior to the session, the reporting participant had to share a written report with the group members and the trainer. This preparatory task had two advantages: (1) the reporting school leader could structure the case clearly and (2) the trainer and peers could prepare themselves for the upcoming session. The written preparatory report included a paragraph on the context, the facts, the experience of the school leader and the learning 
effects thus far. The sessions were divided in several phases. First, the session started with an update on the case focusing on facts. Second, after providing the group with the lie of the land, the trainer and the peers assisted the school leader in the reflection process through asking clarifying questions and adding, predominantly by the trainer, relevant theoretical frameworks until the particular issue was clear. Third, the reporting school leaders and other members were given a moment to write down their perceptions about the central issue. Fourth, every participant shared his/her opinion with the reporting school leader who carefully listened to the various opinions. Fifth, the reporting school leader reflected on the opinions of the peers and determined the scope of the further process. Sixth, peers got room to share relevant experiences. This phase focused on recognition and personal learning experiences with regard to the specific case. The session concluded with a wrap up. Every participant reflected on their personal learning during the session and specified what they were planning to do with the gained insights in practice. Finally, the reporting school leader concluded the session and reported on how the school leader experienced the session, reported on the learning gains and the planned actions to get started with the case.

In the subsequent session, the reporting school leader was questioned on what he/she have put into practice in order to facilitate transfer of training. To ensure the learning and transfer of learning of all participants, every participant had to write a review report on the session that was shared with the group members and was discussed briefly in terms of (learning) experience in the following session (Step et al., 2018). Summarised, the design takes into account school leaders' personal needs and context by letting them select their own case (Authors 1).

Reflecting on cases from school leaders daily practice, allows school leaders to get a deeper insight resulting in problem-solving. Hence, the programme shows similarities with action learning. Action learning is a process in which diverse teams consisting of peers or colleagues search for solutions for real life problems (Marquardt et al., 2009; Pedler, 1997). By means of action learning, the participants learn with and from each other by working and reflecting on real life problems and experiences (Mc Gill \& Beaty, 2001). Action learning assumes self-development and organizational development (Pedler, 1997). Marquardt (2011) suggests the following features of action learning to attain powerful action learning for leaders: action learning (1) starts from a problem, challenge or task; (2) takes place in groups of 4-8 people; (3) comprises a questioning and reflective process; (4) aims to develop strategies and actions; (5) is supervised by a trainer or coach; and (6) considers individual learning, team learning and organizational learning. The features of action learning are present in the current programme as well. However, a difference can be noticed because the group reflective learning programme focuses on school leaders' individual learning, rather than organizational learning. It is assumed that school leaders' individual learning can influence organizational learning or organizational development.

To achieve an effective learning process, the technique of 'core reflection' is used (Korthagen \& Vasalos, 2005). Core reflection is a deep reflection technique and moves beyond superficial and predominant rational approaches. Core reflection includes one's thoughts and feelings in the process, and focuses on nurturing the relation between a person's core qualities and experiences in his/her professional life.

Core reflection is inspired by positive psychology and aims at building on people's strengths and positive feelings. Core reflection leaves room for an analysis of a particular case, but focuses on creating room for new possibilities and considering the ideal situation including the resources that people need to achieve the ideal situation (Korthagen \& Vasalos, 2005). The technique of core reflection focuses on people's internal obstacles who limit the enactment of one's inner potential. Instead of fighting these obstacles, core reflection teaches a person to be mindful about their effects and connecting with the will to change (Korthagen Professional Development, n.d.).

The group reflective learning programme takes into account the recommendations of learning with peers and learning outside the own school (Authors, 1; Hulsbos et al., 2016). Moreover, the quality of the trainer is important (Dyke, 2014). Hence, we carefully considered the appointment of a quality and 
experienced trainer (see above). 'The quality trainer' is a multiple construct. A quality trainer (1) is someone who manages to keep the group focused on the reflection process; (2) is able to add relevant theories during the process, (3) ensures that everyone participates in an equal way; (4) is experienced in training people and has been successful in training people. Carrying out training in a successful way is understood as succeeding the training and improving practices related to the training. Lastly, the training was spread over several months and in this way, the group reflective learning programme meets the advice for training to be spread over time (Authors, 1).

\section{Research Question}

The first level of Kirkpatrick's model of evaluation training is considered as an important level. Indeed, if participants perceive the programme as irrelevant or inappropriate, the programme has only little chance to influence the participants. Hence, the current study thoroughly researches school leaders' responses to the programme and addresses the following research question:

What were the school leaders' reactions with regard to the group reflective learning programme?

The research question is of qualitative nature that fits the aim of the current study: thoroughly researching the responses of the programme. Researching the responses to the programme in depth, will allow one to carry out follow up studies on the other levels, but also provides one with valuable feedback that helps one to evaluate and improve group reflective programmes, to advocate or not about group reflective learning programmes, and can provide one with information to establish standards of performance for future programmes (Kirkpatrick \& Kirkpatrick, 2006).

\section{Methodology}

\subsection{Participants}

The sample was assembled via 'purposive sampling'. Purposive sampling was used to ensure homogeneity of the sample with regard to the school leader - teacher ratio in the participating primary schools varying from 1:20 - 1:35 $(\bar{X}=27,15)$. Apart from sampling for homogeneity, aligning with the average school leader - teacher ratio in primary schools in Flanders, a variety of school leaders with regard to seniority, geographical location (highly urbanized versus less urbanized) and umbrella organization was taken into account to elicit rich reflective discussions.

The average seniority of the school leaders in the position of school leader was 7.10 years ranging from 2 years up to 19 years. The ages of the school leaders ranged from 37 to 54 years with an average age of 45.15 years. The sample consisted of 6 male and 13 female school leaders. The sample was developed by inviting all 2143 primary school leaders whose details were available via the Flemish ministry of education to participate in the study. The primary school leaders were asked to participate in an interview. Initially, 70 school leaders replied and based on the school leader - teacher ratio and geographical spread, 24 primary schools were selected. After detailed explanation of expectations of participating in the training and study, eventually 22 school leaders participated in the group reflective learning programme. One school leader dropped out after the first session due to job turnover and two school leaders dropped out halfway through the process due to prolonged sick leave. All participants signed for informed consent. The informed consent clearly described the interview procedure and the researchers invited the participants to ask questions before the interview started. The participants voluntarily took part and confidentially was assured.

\subsection{Data collection}

The data were collected using semi-structured interviews. An interview guide was used to allow the pursuit of methodological consistency and the contribution to the similarity of the interviews (Cohen et 
al., 2011). The interview guide consisted of open questions to encourage informants to describe situations and experiences extensively and independently. The interview guide was carefully designed and tested in various phases with doctoral students and primary school leaders. Their suggestions were used to adjust the interview guide. For a translation of the main questions from the interview guidance, see appendix A. The questions were of an open nature. The interviewees responded predominantly in a positive way, but were incited to think about the less positive or negative experiences as well.

A flexible attitude was adopted in terms of location, date and time for the interviews. This eased the participants and involved them from the beginning. Almost all interviews were conducted at the participants' workplace and lasted 20 to 60 minutes. One participant preferred to hold the interview at the researchers' workplace. According to Mc Evoy (1997), trainees often tend to complete professional development programmes in a state of euphoria, and as such, their prompt reaction is much higher than feedback reactions measured later. Hence, the interviews were taken three - six weeks after the programme ended.

\subsection{Data-analysis}

The interviews were audio-recorded and transcribed verbatim. The transcriptions were presented to the participants for member validation (Torrance, 2012). During the literature review, some sensitizing concepts came to our attention and were included in the field notes. The sensitizing concepts are indicated in the final coding tree, by means of an asterisk.

First, all transcripts were thoroughly read keeping the research question in mind in order to get a clear insight, and derive codes for the coding tree (see table 1 in appendix B). Based on this focused reading, relevant codes were selected per research question. These relevant codes were finally checked for suitability and eventually the coding tree was drafted. The initial coding tree was compared with the sensitizing concepts of the field notes, however no concept needed to be added based on this comparison. During the initial development phase of the coding tree, the explanations of the codes were drafted as well and discussed with two peers in order to ensure clarity of code clarifications. Subsequently, the transcriptions were analysed using NVivo11. To thoroughly explore the data and let additional codes emerge, the transcriptions were coded inductively. The coding relied on the interpretation of one of the researchers and was supplemented by a search based on the nouns and verbs appearing in the coding tree in order to assure a structured coding and to prevent researcher bias. The coding results were discussed after the first coding round. To ensure that the coding was meticulously carried out, a second coding was done, though it barely resulted in extra codes or extra coded citations.

\subsection{Trustworthiness of the study}

Various characteristics of qualitative research were taken into account to ensure the trustworthiness of the current study. Trustworthiness refers to the fact that the data analysis and the forth-coming results represent a plausible representation of the participants' explanations and exemplifications. Lincoln and Guba (1985) summarize it in an overarching question: 'How can an inquirer persuade the audience, that the findings of an inquiry are worth paying attention to?' (p. 290).

Triangulation was ensured through the inclusion of data from interviews, the interviewer's field notes and the scientific literature. The field notes acted as an aid to develop a broader insight in the collected material and determined codes. Criticality and thoroughness were pursued by repeated readings of the transcripts, the detailed description of the data-analysis, explanations of the codes to ensure an unambiguous coding process, and peer feedback leading to a thorough understanding of school leaders' responses on the group reflective learning programme. Confirmability refers to the fact that the findings emerge from the participants and are predominantly shaped by the participants rather than by the researchers. Confirmability aligns with credibility which refers to the 'truth' of the data or the participant views and representation of them by the researcher (Polit \& Beck, 2012). Confirmability was addressed using rich and vivid quotes from the transcriptions. To ensure accuracy of interpretations, the coding process was carried out through the use of the coding table (see table 1 in appendix B). The dependability of the research, i.e. the findings are consistent and could be repeated, is ensured because 
the sample, experiment and data analysis are described in detail. Furthermore, data saturation occurred after 10-11 interviews, which refers to the fact that there is little chance that other codes would have emerged from a larger sample.

\section{Findings}

School leaders' findings about the group reflective learning programme are clustered into three groups: (1) preconditions that are considered as important by the participants; (2) recognition and support; (3) and the learning-oriented perceptions. To meet the criterion of credibility and to exemplify the subcategories of the three groups, quotes derived from the transcripts are included in the following paragraphs.

The overall reaction of all school leaders $(n=19)$ about the group reflective learning programme was positive. They all expressed predominantly positive feelings about the programme and stated that they were satisfied that they participated.

"I would sign up for a follow-up trajectory immediately. This was very meaningful to me." [School leader 17, male, 7 years of experience]

"Yes, very positive. It affected me in a positive way. I loved to go to the sessions." [School leader 2, female, 19 years of experience]

While asking the school leaders how they perceived the group reflective learning programme, they spontaneously named some preconditions. For a clear understanding, the school leaders did not name this as a precondition but explained that they experienced this as a valuable feature of the programme. Ten participants indicated the importance of team psychological safety as an important aspect of the positive experience with the programme. Some participants explicitly added that they needed to feel safe in order to open up and share nasty real life situations.

"From the start we were a 'safe group'. I genuinely felt ... whether I say or do here, it stays between us. You will not show your vulnerability that easy with a school leader from the same village." [School leader 3, female, 2 years of experience]

"A positive thing to me was the safe atmosphere. Nobody knew each other. That is important. If you have school leaders from the same area ... if you have a good relationship, you talk, but that is different. So, it was definitely an added value that no one knew each other." [School leader 16, male, 16 years of experience]

"We had a good group. I experienced an atmosphere of trust; we could tell each other everything." [School leader 19, male, 15 years of experience]

Furthermore, the importance of the quality of the trainer was named by nine participants in order to structure the process, to prevent complaining chats, which may result in dead ends and to add relevant theories to get a deeper insight in the studied case. The participants valued the trainer frequently.

"To continue to organize that, a programme with a trainer is a necessity, not without. Without a trainer, the programme will end up in a meaningless chat. The added theory and the professional approach from someone 'outside' is important. Professionals must be appointed for that. We should not be coached by our school board or a colleague." [School leader 2, female, 19 years of experience]

"Our trainer advised us to think twice, to go the extra mile and she enforced deep thinking. It usually remains rather superficial when you share a problem with colleagues. They nod, recognize it and that's it. But due to the presence of the trainer, solutions were sought." [School leader 7 , male, 4 years of experience] 
"Gosh, the trainers must be of an extreme high-quality, like our trainer. According to me, that is very important." [School leader 8 , female, 13 years of experience]

The group diversity was perceived as an important factor of the positive experiences with the group reflective learning programme. The diversity of the group widens school leaders' perspectives on issues and widens their views. School leaders also seem to feel eased by the experiences of peers and no longer blame their context and lack of experience. They start to realize that every school has its issues. Eight participants named the easing effect as something they appreciated in the training and linked it to the diversity of the group. More experienced school leaders referred that they felt eased because similar cases happened in other contexts too, whereas less experienced school leaders referred to the seniority of other school leaders and explained that they felt eased because they noted that senior school leaders experience similar cases as well and it is not due to their lack of experience. Furthermore, some school leaders operating in a highly urbanised environment, which is usually perceived as a more demanding context, also referred to the fact that they felt eased by stories of colleagues who experienced similar cases in more rural areas.

"I feel more confident now. And the easing effect of the insight that we do not always know the answer and that even senior school leaders still encounter those problems ... and yes, that comforted and eased me. And with regard to content and material, I got so much tools to tackle a number of problems." [School leader 14, female, 2 years of experience]

"I find it nice to hear, that it is not only in my city that the children react in this particular way, or that teachers behave like this or that. Because sometimes you blame your context. And then I think ... it is everywhere." [School leader 1, female, 2 years of experience]

The second cluster, consists of 'recognition' and 'support' from fellow school leaders. The codes are interconnected and sometimes mentioned together. Recognition was named by eleven school leaders and is mentioned the most frequently in answering the question on how they perceived and experienced the group reflective learning programme. Some school leaders described recognition related to its easing effect and the soothing of feelings of loneliness.

"The reassurance of recognition of cases of other school leaders. It comforts ... that it happens at their schools as well, in a total different context, that they have sometimes some clashes too." [School leader 9, female, 9 years of experience]

"It is about recognition; you notice that you are not the only one in the world who experiences those difficulties. Others are struggling too." [School leader 18, female, 2 years of experience]

Another emerging perception is supporting peers and the support received from peers $(n=6)$. School leaders explain examples of deep listening, properly analysing the exemplified case, concrete advice in solving problems and comforting peers when unravelling the causes.

"The strengths of the group reflective learning programme, once again ... the exchange and support of each other, deep listening, and the analysis of each phase of every case in a proper way." [School leader 10, female, 14 years of experience]

The participants also expressed their enjoyment of the learning-oriented experiences. The school leaders $(n=7)$ valued learning from experiences. They named that it was interesting to learn from their own and from others' experiences. They valued the group reflective learning programme because it built on their own daily-life experiences.

"It is important, that trainings are more concrete. They should start from existing, real life situations, from situations of school leaders like us. That is very fruitful, yes!" [School leader 18 , female, 2 years of experience] 
School leaders $(n=6)$ also indicated enjoyable learning experiences in terms of possibilities to learn thanks to their participation in the group reflective learning programme. Some explained that they were grateful to learn from the supporting theoretical frameworks introduced by the trainers, whereas some others preferred to learn from the experiences of their colleagues. The link with the theoretical frameworks was also valued by school leaders $(n=5)$ in more general explanations when valuing the programme. The school leaders named it as a general positive feature of the programme or as a feature that helped them to get more insight into a particular case.

"The positive aspect is the theoretical approach and the valuable input." [School leader 12, male, 6 years of experience]

"The input during the training, the literature, that is interesting, that is something I can learn." [School leader 10, female, 14 years of experience]

School leaders $(n=6)$ also indicated that they found it meaningful to learn to approach cases from different viewpoints. Additionally, some school leaders exemplified that it eased them and removed tension from the situation resulting in a case that was easier to tackle.

"It is good to talk substantively with like-minded people. Sometimes they have a different opinion, that broadens your own vision and eventually you look at it differently. I support that, I learn the most from that." [School leader 17, male, 7 years of experience]

Lastly, the participants valued the possibility of reflecting about their position and role as school leader $(n=6)$. It helped them to get an increased understanding of their position and to eventually feel more confident and act more effectively at the workplace.

"And that is a mirror that comes very close and that stimulates you ... am I doing it in the right way? Do I have to change it? Do I have to act faster? Do I have to involve others or not? It is a very good exercise. A good mirror for myself as school leader, to see ... is this okay?" [School leader 14, female, 2 years of experience]

"So, we could reflect about ourselves. We are ... I got a better insight in myself. I became more self-confident in some ways." [School leader 2, female, 19 years of experience]

Gauging the school leaders' experiences with the group reflective learning programme was based on open-ended questions supplemented by questions inciting positive and negative experiences. The answers were predominantly of a positive nature; however, some school leaders added critiques. Three school leaders indicated that they would have liked to have time to exercise conversation techniques related to coaching, one school leader explicitly referred to the use of role-plays. Another comment expressed by three school leaders was that they felt pressure to leave their schools and found eight sessions of 2.5 hours spread over seven months rather excessive. One school leader indicated explicitly that the additional tasks caused time management issues and were demanding.

\section{Discussion}

One main research question guided this study: 'What were the school leaders' reaction with regard to the group reflective learning programme?' The findings show that the participants experience this type of programme as meaningful. A positive response to professional development activities is relevant to achieve deep learning (Kirkpatrick, 1994; Phillips, Stone \& Phillips, 2001) eventually resulting in possible learning results and organizational change (Kirkpatrick, 1994). The school leaders agree on the importance of recognition, which refers to easing school leaders and soothing their feelings of loneliness. This aligns with the recommendations for the development of effective professional development for school leaders of Authors (1) who state that networking and collegial consulting reactivates knowledge and eases feelings of loneliness. Additionally, this corresponds with the statement of Aas \& Vavik (2015) and Flückiger et al. (2017) who point to the importance of 
connectedness to others and the power of the group of establishing school leaders' continuous professional development. The participants also expressed their enjoyment of learning. Apart from that, the school leaders expressed some preconditions for the success of a group reflective learning programme and mentioned the importance of psychological safety, the role and quality of the trainer to steer the programme, and the diversity of the group to widen their views resulting in an easing effect. Other authors also described the preconditions expressed by the participants. For instance, Sanner \& Bunderson (2015) referred to the importance of psychological safety in team learning. Aas \& Vavik (2015), Dyke (2014) and Korthagen \& Wubbels (2001) emphasized the role of the trainer in order to induce reflective learning and prevent for superficial informal chats. These results are meaningful in three ways. First, the predominantly positive responses of the participating school leaders show that the programme has the potential to effectively improve the participants' knowledge, skills, attitudes and behaviour which will possibly result in a change of the overall school performance (Kirkpatrick, 1994). Second, the results provide us with a deeper insight in school leaders' perceptions of preconditions of these particular kinds of programmes and it will allow shaping future group reflective learning programmes. Third, the results show that these participants enjoy the programme and the included learning activities. The school leaders show eagerness to learn and that explained that they especially enjoyed reflecting about their own position and valued the link with the theoretical frameworks. In addition, the different viewpoints from the peers were appreciated. Fourth, group reflective learning seems to satisfy the statement that school leaders need to be supported and provided with appropriate professional development programmes to prevent job related psychosocial issues (Devos et al., 2018; Elmore, 2000; La Pointe \& Davis, 2006). The findings in the study indicate that group reflective learning can contribute to lower feelings of stress among school leaders, but to state this convincingly follow up research including a larger sample and a more focused questionnaire is needed.

\section{Conclusions}

Little is known about school leaders' group reflective learning, hence a qualitative approach was used to generate an insight in school leaders' responses to group reflective learning. Given the predominantly positive responses on the group reflective learning programme, further research considering the higher sequenced levels of Kirkpatrick's model is worth being carried out. Indeed, based on the outcomes of the current study, it can be stated that group reflective learning programmes have the potential to be successful. The participants enjoyed the programme and indicated the programme as relevant and appropriate. According to Kirkpatrick \& Kirkpatrick (2006) this positively affects the participants learning motivation which was also reflected in the inquisitiveness the participants showed in their answers. Further studies, taking into account the higher sequenced levels of Kirkpatrick's model, will determine whether the participants transfer gained knowledge, skills and/ or attitudes into practice. The findings of the current study also give cause to invest in the development of (assessment tools for) group reflective learning programmes for school leaders.

While reasonable efforts have been made to conduct a trustworthy study, the study has some limitations. The limitations are relevant to take into account, when one would like to generalize the findings or would like to transfer it into practice. While compiling the sample, a self-selection effect may have occurred. Every Flemish school leader was allowed to participate in the study, but the participants have committed themselves to participate in the programme. While applying for the programme, school leaders had to indicate their motivation to participate in the programme. Subsequently, their motivation was gauged in a detailed explanation. Hence, the sample might consist of the most inquisitive primary school leaders. All participants were granted free participation in the programme because the programme had research purposes. The interviewer incited the participants to provide the interviewer with honest and critical feedback in order to carry out valuable scientific research, some school leaders, who are genuinely perceived as critical people, might have responded slightly more positive than usual. The positive reactions may also be linked to the feelings of elation because they found a platform to share their doubts and found a solution for their problem(s). The study relies on school leaders' self- 
reporting data. Self-reporting data recall sensitivity to bias such as social desirability, recall period and selective recall. The transcripts of the interviews were presented to the participants with the request to provide feedback. This request allowed to level out some bias caused due to issues of recalling during the interview. A few school leaders provided some additional information. However, self-reporting data are valuable data when gauging perspectives and opinions likewise in the current study.

\section{References}

Aas, M. \& Vavik, M. (2015). Group coaching: A new way of constructing leadership identity? School Leadership \& Management, 35(3), 251-265.

Aas, M. (2016). Leaders as learners: Developing new leadership practices. Professional Development in Education, 43(3), 439-453.

Battle, D. (2010). Principal attrition and mobility: Results from the 2008-09 Principal Follow-up Survey (NCES 2010-337). U.S. Department of Education, National Center for Education Statistics. Washington, DC: U.S. Government Printing Office.

Cohen, L., Manion, L., \& Morrison, K. (2011). Research methods in education. London/New York: Routledge.

Authors 1

Authors 2

Authors 3

Daudelin, M. (1996). Learning from experience through reflection. Organizational Dynamics, 24(3), $36-48$

DeSilets, L. (2018). An update on Kirkpatrick's model of evaluation: Part two. The Journal of Continuing Education in Nursing, 49(7), 292-293.

Devos, G., Vanblaere, B. \& Bellemans, L. (2018). Stress en welbevinden bij schoolleiders: Een analyse van bepalende factoren en van vereiste randvoorwaarden. Retrieved, August 22, 2019, from https://dataonderwijs.vlaanderen.be/onderwijsonderzoek/?nr=941

Donaldson, G. (2008). How leaders learn: Cultivating capacities for school improvement. New York: Teachers College Press.

Drago-Severson, E. (2012). The need for principal renewal: The promise of sustaining principal through principal-to-principal reflective practice. Teachers College Record, 114(12), 1-56.

Dyke, P. (2014). Virtual group coaching: A curriculum for coaches and educators. Journal of Psychological Issues in Organisational Culture, 5(2), 72-86.

Edmondson, A. (1999). Psychological safety and learning behavior in work teams. Administrative Science Quarterly, 44(2), 350-383.

Edmondson, A. (2008). The competitive imperative of learning. Harvard Business Review, 86(7,8), 60 67. Retrieved from http://hbr.org.

Elmore, R. (2000). Building a new structure for school leadership. Washington, DC: Albert Shanker Institute. 
Flemish Ministry of Education. Officieel en vrij onderwijs, onderwijsnetten en koepels. Retrieved November 2, 2019, from https://www.vlaanderen.be/onderwijs-en-vorming/organisatie-van-hetonderwijs/structuur/officieel-en-vrij-onderwijs-onderwijsnetten-en-koepels.

Flückiger, B., Aas, M., Nicolaidou, M., Johnson, G. \& Lovett, S. (2017). The potential of group coaching for leadership learning. Professional Development in Education, 43(4), 612-629.

Fullan, M. (2009). Motion leadership: The skinny on becoming change savvy. Thousand Oaks, CA: Corwin/Sage.

Good, T. and Brophy, J. (1994). Looking in classrooms. Harper Collins College Publishers, New York, NY.

Hawkins, P. (2014). Leadership team coaching in practice: Developing high-performing teams. London: Kogan Page.

Huber, S. (2011). The impact of professional development: A theoretical model for empirical research, evaluation, planning and conducting training and development programmes. Professional Development in Education, 37(5), 837-853.

Hulsbos, F., Evers, A. \& Kessels, J. (2016). Learn to Lead: Mapping workplace learning of school leaders. Vocations and Learning, 9(1), 21-42.

Inel, D., Balim, A. (2010). The effects of using problem-based learning in science and technology teaching upon students' academic achievement and levels of structuring concepts. Asia-Pacific Forum on Science Learning and Teaching, 11(2), 1-23.

Kirkpatrick, D. (1959). Techniques for evaluating training programmes. Journal of the American Society of Training and Development, 1(11), 3-9.

Kirkpatrick, D. (1994). Evaluating training programmes: The four levels. San Francisco: BerrettKoehler.

Kirkpatrick, L. \& Kirkpatrick, J. (2006). Evaluating training programmes: The four levels. San Francisco: Berret-Koehler.

Korthagen Professional Development (n.d.). Core reflection and multi-level learning. Retrieved January 16, 2020 https://korthagen.nl/en/focus-areas/core-reflection-multi-level-learning/.

Korthagen, F (1993). Two modes of reflection. Teaching and Teacher Education, 9(3), 317-326.

Korthagen, F. (2004). In search of the essence of a good teacher: Towards a more holistic approach in teacher education. Teaching and Teacher Education, 20, 77-97.

Korthagen, F. \& Kessels, J. (1999). Linking theory and practice: Changing the pedagogy of teacher education. Educational Researcher, 28(4), 4-17.

Korthagen, F., Kessels, J., Koster, B., Lagerwerf, B. \& Wubbels, T. (2001). Linking practice and theory: the pedagogy of realistic teacher education. Mahwah, NJ: Lawrence Erlbaum Associates.

Korthagen, F. \& Vasalos, A. (2005). Levels in reflection: Core reflection as a means to enhance professional growth. Teachers and Teaching, 11(1), 47-71.

Korthagen, F., \& T. Wubbels. 2001. Evaluating research on the realistic approach and on the promotion of reflection. In Linking Practice and Theory: The Pedagogy of Realistic Teacher Education, ed. F. Korthagen, 88-107. Mahwah, NJ: Lawrence Erlbaum Associates. 
LaPointe, M., \& Davis, S. (2006). Effective schools require effective principals: A study of professional development for principals offer these findings about the qualities and impact of strong programmes. Leadership, 36(1), 16-19.

Lincoln, Y. \& Guba, E. (1985). Naturalistic Inquiry. Newbury Park: Sage Publications Inc.

Marquardt, M., Leonard, H., Freedman, A., \& Hill, C. (2009). Action learning for developing leaders and organizations: Principles, strategies, and cases. Washington, DC: American Psychological Association.

Marquardt, M. (2011). Optimizing the power of action learning. Boston, MA: Nicholas Brealey.

Meisel, S. (2012). The constructivist approach to learning. Organization Management Journal, 9(4), 247-248.

McEvoy, G. (1997). Organizational change and outdoor management education. Human Resource Management, 36(2), 235-50.

McGill, I., \& Beaty, L. (2001). Action learning: A guide for professional, management \& educational development. Sterling, VA: Stylus Publishing.

Mitchell, R. (2013). What is professional development, how does it occur in individuals, and how may it be used by educational leaders and managers for the purpose of school improvement? Professional Development in Education, 39(3), 387-400.

Normore, A. (2007). A continuum approach for developing school leaders in an urban district. Journal of Research on Leadership Education, 2(3).

Passmore, J. (2013). Cross-culture and diversity in coaching. In Diversity in Coaching: Working with Gender, Culture, Race and Age, edited by J. Passmore, 1-10. London: Kogan Page Ltd.

Paulus, P. \& Nijstad, B. (2010). Group creativity: Innovation through collaboration. New York, NY: Oxford University Press.

Pedler, M. (1997). Action learning in practice. Burlington, VT: Gower Publishing.

Peterson, K. (2002). The professional development of principals: Innovations and opportunities. Educational Administration Quarterly, 38(2), 213-232.

Phillips, J., Stone, R. \& Phillips, P. (2001). The human resources scorecard. Measuring the return on investment. Boston: Butterworth-Heinemann.

Polit, D. \& Beck, C.T. (2012). Nursing research: Generating and assessing evidence for nursing practice. Philadelphia, PA: Lippincott Williams and Wilkins.

Sanner, B. \& Bunderson, J. (2015). When feeling safe isn't enough: Contextualizing models of safety and learning in teams. Organizational Psychology Review, 5(3), 224-243.

Step, I., Depuydt, A., Mertens, S. Delathouwer, B. \& Author (2018). Supervisiegids. Nascholing directies basisonderwijs.

Stevenson, M., Hedberg, J., O’Sullivan, K. \& Howe, C. (2016). Leading learning: The role of school leaders in supporting continuous professional development. Professional Development in Education, 42(5), 818-835.

Torrance, H. (2012). Triangulation, respondent validation and democratic participation in mixed methods research. Journal of Mixed Methods Research, 6(2),111-123. 
Van den Bossche, P., Gijselaers, W., Segers, M. \& Kirschner, P. (2006). Social and cognitive factors driving teamwork in collaborative learning environments. Small Group Research, 3(5), 490-521.

Vlaamse Onderwijsraad. [Flemish Education Council] (2003). Advies over zorgcoördinatie in het basisonderwijs. Retrieved, September 10, 2019, from https://www.vlor.be/adviezen/zorgcoordinatiehet-basisonderwijs.

Windham, D. \& Chapman, D. (1990). The evaluation of educational efficiency: Constraints, issues, and policies. Greenwich: JAI Press Inc.

Youngs, P. \& King, M. (2002). Principal leadership for professional development to build school capacity. Educational Administration Quarterly, 38, 643-670.

\section{Appendix}

\section{Appendix A}

Main interview questions with regard to the reaction level

How did you experience the group reflective learning programme?

What is your most important experience in relation to the programme?

What could be improved about the group reflective learning programme?

Which advice would you give about the programme if you could report to school board and/or umbrella organizations about the programme?

\section{Appendix B}

Table 1

Code clarifications to tackle school leaders' reactions on the group reflective learning programme

\begin{tabular}{l|l}
\hline 1. Qualitative trainer* & A trainer who manages to keep the group
\end{tabular} focused on the reflection process and who is able to add relevant theories during the process. (Authors' definition)

2. Team psychological safety*

"Team psychological safety is defined as a shared belief that the team is safe for interpersonal risk taking." (Edmondson, 1999, p.5)

3. Diversity of the group members

The groups were composed taking into account a variety of umbrella organizations, seniority and geographical spread. (Authors' definition)

4. Recognition

Recognition refers to the fact school leaders recognize situations that peers encounter as well. (Authors' definition)

5. Support from fellow school leaders

Support from fellow school leaders refers to gaining new perspectives, increasing efficiency, becoming more innovative through the presence 


\begin{tabular}{|c|c|}
\hline & $\begin{array}{l}\text { and support from fellow school leaders. } \\
\text { (Authors' definition) }\end{array}$ \\
\hline 6. Learning from own experiences and peers* & $\begin{array}{l}\text { The particular learning experiences based on } \\
\text { cases, examples, advices or questions from own } \\
\text { experiences and/or group members. (Authors' } \\
\text { clarification.) }\end{array}$ \\
\hline 7. Possibility to learn & $\begin{array}{l}\text { School leaders value the different learning } \\
\text { activities, options to learn or express their } \\
\text { inquisitiveness. (Authors' clarification.) }\end{array}$ \\
\hline $\begin{array}{l}\text { 8. Approach the situation from another point of } \\
\text { view* }\end{array}$ & $\begin{array}{l}\text { Exposure to the experiences of school leaders } \\
\text { from various schools develops 'cultural } \\
\text { competence'. Cultural competence includes the } \\
\text { ability to respond in an open-minded way to } \\
\text { other people's ideas and be willingly to question } \\
\text { one's own assumptions and the assumptions of } \\
\text { other group members (Passmore, 2013). }\end{array}$ \\
\hline 9. Reflecting about the own position* & $\begin{array}{l}\text { Reflection an activity in which 'an individual } \\
\text { steps back from experiences in order to analyse } \\
\text { the meaning to the self' (Hulsbos, Evers \& } \\
\text { Kessels, 2016; Daudelin, 1996). Aas (2016) } \\
\text { defines reflective learning as 'the critical } \\
\text { investigation of an individual's own practice in } \\
\text { order to provide professional learning and } \\
\text { development'. }\end{array}$ \\
\hline 10. Link with theory & $\begin{array}{l}\text { Referring to the trainer who introduces links to } \\
\text { theoretical frameworks and theories to clarify or } \\
\text { better understand the presented cases. (Authors' } \\
\text { definition) }\end{array}$ \\
\hline $\begin{array}{l}\text { 11. Human approach of the fellow school } \\
\text { leaders }\end{array}$ & $\begin{array}{l}\text { A positive, respectful and empathic approach of } \\
\text { the fellow school leaders in the group. (Authors' } \\
\text { definition) }\end{array}$ \\
\hline 12. Not at the own school & $\begin{array}{l}\text { The school leaders, who indicated this, valued } \\
\text { the fact that the trajectory took place out of their } \\
\text { own school environment and emphasized that } \\
\text { this facilitated their learning process. (Authors' } \\
\text { clarification.) }\end{array}$ \\
\hline 13. Based on own experiences* & $\begin{array}{l}\text { This node compiles quotes referring to the } \\
\text { starting point of the trajectory: school leaders' } \\
\text { own experiences and difficulties to find } \\
\text { eventually options to proceed or in the best-case } \\
\text { solutions. (Authors' clarification.) }\end{array}$ \\
\hline $\begin{array}{l}\text { 14. Accompanying tasks (preparatory and wrap } \\
\text { up writing tasks) helped to structure and } \\
\text { facilitate the reflective process. }\end{array}$ & $\begin{array}{l}\text { For the sake of the professional development } \\
\text { trajectory, the participating school leaders were } \\
\text { asked to write a summary of the case they } \\
\text { wanted to discuss. After every training session, }\end{array}$ \\
\hline
\end{tabular}


the school leaders had to write a report in which they addressed their learning experiences and reported on how to turn into practice what they had learned. (Authors' clarification.) 